\title{
A community of fans, friends and power-users
}

Sustainable E-Participation in Estonia

\author{
Hille Hinsberg \\ Estonian Government Office, hille.hinsberg@riigikantselei.ee
}

\begin{abstract}
Estonia is recognised as a beacon of E-Government achievement and is making strides in using technology to include citizens in democratic processes. The key to sustainable E-Participation is to ensure that all E-Participation initiatives contribute to establishing an overall community of Wikipedia-like users who believe that their commitment and investment of time really makes a difference. Over time, citizens' roles and contributions may vary a lot, but this essential public infrastructure and policy has to be provided systematically for E-Participation to become a reality - whatever new technology comes along, and however successful individual projects are. This is the real meaning of sustainable E-
\end{abstract}

Keywords: Estonia, E-Participation, case studies, E-Government, community engagement

Acknowledgement: Many thanks for valuable comments: Kristina Reinsalu, Liia Hänni, Sten Hansson, John Heaven, Francesco Molinari

$\mathrm{E}$ -participation has numerous definitions. The common thread seems to be that it provides a channel for citizens' voices and for getting things done together. It's a way for active citizens to express their views and share the responsibility for society's development.

The digital environment - the Internet or, nowadays, rather the web 2.0 toolkit - provides a platform for interacting with the decision-makers. Tim O'Reilly and many others use the term Government 2.0 to mark the change in public sector provision of its information and services. Some prefer the phrase Open Government to encompass general increase in transparency from government, and E-Participation as part of that openness Whichever term, it denotes an understanding that innovations in technology and interactive communication influence the way society works.

E-Participation seems to be one of the lifelines that representative democracies are currently experimenting with, in the hope that it counteracts public disillusionment and fatigue with politics. The promise of E-Participation is the ability of ICT to fulfil some new expectations - for efficiency and accountability in governance. In this article, I refer to E-Participation as using the digital environment to facilitate citizen input in decision-making and community organising.

I will discuss some of the "building blocks", the prerequisites without which E-Participation simply cannot happen. Then I move on to discuss how, if this bedrock of basic infrastructure exists, governments can work towards involving citizens in everything they do by offering participation opportunities that satisfy the diverse demands of citizens, from those who wish to participate a lot to those who wish to participate to a lesser degree. I will conclude by offering some concrete recommendations for governments wishing to achieve this.

The core of my argument throughout is that sustainable E-Participation means painting the big picture, ensuring that any E-Participation project or intervention contributes to the community of EParticipators by providing users with an experience that they would wish to repeat because they feel their investment of time has made a difference. By nurturing a community of power-users, friends and fans similar to the communities that exist elsewhere on the social web - and offering E- 
Participation opportunities suited to everyone who wishes to participate - successive projects and interventions can ensure that there is a rich seam of citizens with which a Wikipedia-style state can collaborate.

\section{A flourishing E-Participation community}

Whenever I am asked about Estonian experience of eGovernment, I do not quite know where to start. Each time the jigsaw pieces fit together a little differently, resulting in a slightly different picture depending on the angle that the question comes from. Could technology be the driver for eGovernment innovation? Does the "secret" lie in the legislative framework and political attitude towards open governance? Or do we need active citizenry and powerful communities to lead the participation initiatives?

Let us look more closely at these building blocks, or prerequisites of technology, institutional mechanisms and citizen initiatives, in the Estonian case.

Once I have described these building blocks, I will set out a vision that will go a good way to ensuring that E-Participation becomes a reality. I will address both of these in the following sections, "the building blocks" and "a vision for the future".

\subsection{The building blocks}

\subsubsection{Technology}

Broadly speaking, E-Participation is dependent upon citizens and government having access to the "right" technology and being able to use it. Because of Estonia's record in deploying EGovernment systems, the " $E$ " is already at the core of government decision-making. As the groundwork has been done, it should be easy for Estonia to promote E-Participation by opening up to the public.

There are many examples of this existing infrastructure: the X-Road secure data exchange layer, which allows data to be held centrally and accessed securely by different E-Government applications, including across agencies; the ID cards that over $80 \%$ of the population possess, enabling both electronic authentication and digital signing; efficient E-tax and E-customs services; government online registers etc. Perhaps the most well-known example is Estonia's E-Voting infrastructure, which is described in more detail in the box below.

Any technological infrastructure that government provides should be "foolproof": i.e. easily understandable, navigable and convenient for users. As easy as this sounds, it does get complicated when programming starts. Quite literally, success comes when people are willing and competent to "play" with e-tools. By doing so, they get engaged in decision-making for society's tough questions - but this is unlikely to happen if technology is overly-complicated and not intuitive. Added to that, there should be resources for constant promotion and help-desks, backed up by the ongoing development of technological features.

Further, it is important that citizens have access to the internet and are able to use it. 75 per cent of Estonians use the internet or email, meaning that the "digital literacy" amongst the population is high.

Similarly, people need the capacity to participate in public life, This can only happen over time, by combining government effort with citizens' gradually rising skills and motivation to use new technologies. When TOM (the Estonian government's first E-Participation platform, see the following box) was first released in 2001, the aim was to replace one-way information flows about the operation of government with interaction between citizens and government as well as citizen-tocitizen communication. But at that time, besides lack of motivation to have a say in "official matters", people did not know how to put forward a self-initiated proposal or where it should be presented. TOM served as intermediary for citizen initiative. 


\subsubsection{Institutionalizing E-Participation}

Another prerequisite for sustainable E-Participation is a favourable legislative and policy framework. In Estonia, the Public Information Act established an important foundation for EDemocracy in 2001, obliging all public institutions to open websites and provide extensive online content of public interest, including drafts of policy documents and legislative acts.

Several important processes for democratic development have stemmed from the Estonian Civil Society Development Concept, adopted in 2002. It is a strategic document defining the mutually complementing roles, mechanisms and priorities for cooperation between public administration and civil initiative.

The concept was complemented by the "Code of Good Practice on Involvement", outlining key principles that support citizen participation. The Code suggests that the main principles of participation should be incorporated into policy planning process. On the other hand, engaging citizens in drafting legislation and preparing policy documents is not mandatory.

Similarly, there is no specific policy on e-democracy/E-Participation.

In 2006, the Government adopted the Estonian Information Society Strategy 2013, which sets out the general framework and objectives for a broad employment of ICT in society.

The strategy focuses on three areas:

1. CITIZENS: the development of citizen-centred and inclusive society, which focuses on broadening access to digital information and improving skills and opportunities for participation;

2. BUSINESS: the development of a knowledge-based economy, which aims to increase ICT uptake in all economic sectors and the competitiveness of the ICT sector;

3. PUBLIC ADMINISTRATION: the development of citizen-centred, transparent and efficient public administration. The public sector functions efficiently while collecting, using and maintaining data necessary for ensuring the provision of public goods in a common and systematic manner.

Having the basic legal framework in place is not only a building block but can lead to tangible results in its implementation.. Public interest in how participation works in practice is continually growing: whether all affected groups have been involved in policy making, whether the dialogue is substantial and whether an agreement is reached. The heightened demand and interest is interrelated with the growth and strengthening of civil society, voicing strongly their own views on state affairs, identifying problems and proposing solutions for urgent matters.

\subsubsection{Citizen initiatives}

It is important that there is demand for participation in government on the part of citizens. After all, E-Participation cannot take place unless citizens want to participate. We know that there is a good demand for participation in Estonia because of the extent of participation in some of Estonia's projects: the My Estonia campaign (described below in the fact box) showed that people are willing to commit themselves for the wellbeing of society if trust is shown in communities and citizen voices count, and the osale.ee consultation portal (see the box for full information) has on average 5,000 readers per consultation and a total of 3,000 registered users. There are other examples too: the entirely citizen-run project Garage48, a competition to build new applications from scratch in just two days. Then there is our experience with E-Voting: despite being a recent phenomenon, in the last local government elections 9.5 per cent of votes were cast over the internet.

\subsection{A vision for the future}

The prerequisites outlined above do not guarantee successful E-Participation; they are simply a sine qua non, without which E-Participation - sustainable or otherwise - cannot happen. 
Governments have to make a concerted effort to work in a way that enables E-Participation in a sustainable manner by fostering the community of users that I mentioned at the start of this paper.

Once a government has laid the building blocks described above, it has built a platform that citizens can participate in. It is interesting to compare citizens to users of other online platforms, where there are "fans", "friends" and "power-users". We learned from the My Estonia campaign (see the box below for more information) that citizen participation is highly voluntary and may never reach $100 \%$, but it is sufficient to form a group of community leaders and activists to start tackling real problems. These are the "power users" that a community of E-Participators needs.

Not everybody will be one of the power users and it is important to ensure that they can participate too. Whereas My Estonia sought to find a group of new community leaders to take the leading role in implementing solutions that came out of a one-day brainstorming event, the project used online tools to support everybody in participating both on- and offline in identifying problems and solutions. Thus, the project recognised that some people wanted to participate more intensely than others and catered for these wishes.

There are many different levels of participation, from zero right up to very time-intensive activism. Estonia offers most of them online. Here is a list of possible types of involvement, roughly ordered from the lowest level of participation to the highest, illustrated by an example of an Estonian case-study where appropriate. (See the case studies, in the body of this paper, for more information about the individual projects.)

- Government information: osale.ee is a platform that all government agencies can use to publish information about legislative and strategy proposals; since 2010 government documentation registers have been made public and full-text searchable

- Elections: starting in 2005, Estonia was the first country to introduce online voting

- Deliberation: the osale.ee portal offers the facility for citizen to citizen interaction, amongst other things

- Pledge bank: an online pledge bank was established as part of the My Estonia project

- Agenda-setting: the prototype VOLIS platform, an information system for local governments, enables fully digital decision-making processes. Citizens can interactively participate in the sessions of the council's commissions and initiate policy proposals; for more information, see the following box

- Citizen-led service design: the My Estonia project uses web 2.0 tools for mapping and delegating services to the local communities and civil society organisations

- Individual initiatives: individual initiatives came out of the My Estonia project, and the MyGarage48 project is an example of an entirely citizen-led participation project for start-up ventures

- Co-working and problem solving, community organising: The My Estonia project formed a group of community activists and leaders, who started addressing issues and solving problems

From the list above, you see that these projects cover almost the entire spectrum of participation intensity, offering opportunities for everybody to participate. This is of central importance to ensuring that a diverse community of E-Participators is maintained. I have included more comprehensive information about the case studies dealt with here and throughout the paper in the section below.

\section{E-Voting}

Estonians were able to vote over the internet in local elections in 2005 and 2009 and in parliamentary elections in 2007. The secure ID card was used as for authentication. E-Voting does 
not aim to replace the traditional voting methods, but provides, with the help of new technology, additional options for political participation. E-Voting was also used in the parliamentary elections in March 2007 and in local government elections 2009. At the last election, over 100,000 (9,5\%) of votes were cast on the web.

Lots of people who ask about E-Voting are concerned about security issues. But the security of E-Voting infrastructure has been proved thoroughly. But it is not only technologically that Estonians can feel secure and independent in their choice. It may also be that we trust the digital channel as an objective vote-counting system, as opposed to corrupt voting procedures of Soviet times.

There has been too little research into E-Voting in general to draw definitive conclusions in terms of its actual influence. Nevertheless, according to Vassil's analysis (Vassil, 2007) of Estonian E-Voters, the number of people whose participation depended on e-channel is small but present: 10 per cent of the e-voters claimed that they would not have voted offline. 95 per cent of e-voters were convinced that they would not like to vote in the traditional way if e-voting continues to be available (Vassil, 2007).

\section{TOM}

TOM ("Today I Decide"), now superseded by osale.ee, was the Government's first attempt to engage people in decision-making electronically in order to increase participation in social issues and thereby narrow the gap between the government and the governed.

With direct support of the Prime Minister and backed by communication professionals, TOM was an attempt at building bilateral communication with constituencies, making government more transparent to citizens. TOM was designed to serve interaction between citizen and government through allowing official comments and responses to citizens' ideas, as well as citizen-to-citizen communication. The international version "Today I Decide +" (TID+) is in use in Slovenia.

\section{osale.ee}

The Estonian Government's central participation portal www.osale.ee ('osale' means 'participate' in Estonian) was launched in 2007, allowing interest groups and individuals to comment on draft policy documents, launch their own ideas and initiatives for new legislation and amendments, and submit petitions. Other users can vote and comment on these proposals. Then the proposal is forwarded to the relevant government department, which in turn posts an answer, explaining what action was or was not taken and why.

Government agencies are regularly advised how to publish draft policy papers, development plans, laws or provisions on the consultation website. This is voluntary, so some ministries are more active than others in publishing consultations. Many still prefer to email the draft legislation to selected non-governmental partners known for their expertise in advocating their members' interests.

Each year, on average 25 public consultations have been carried out, initiated by all ministries and the Government Office. Interest in the consultations is quite significant: the website has 5,000 visits per consultation on average and over 3,000 registered users overall. Among them are individual citizens and representatives of civil society organizations.

\section{VOLIS}

VOLIS is a prototype information system for local councils. Currently in testing, it is a novel software solution connecting E-Participation with official decision-making. VOLIS enables fully digital decision-making processes within councils. It enables citizens to interactively participate in the sessions of the council's commissions, and to initiate policy proposals for the agenda. Based on the internet, the functionality gives access to the documents and necessary information whatever the location. All the relevant information can be searched and accessed through the same channel. 


\section{My Estonia}

"My Estonia" is a good example of digital engagement supporting offline community organising. The initiative was designed as a one-day brainstorming event where people were called upon to identify and discuss issues that matter most to them in their localities, in the era of economic recession. Brainstormers discussed issues of their choice, coming up with solutions and not just problems. They then move into smaller thematic workshops to elaborate solutions and take matters forward. Organisers provided 400 brainstorming sites where over 11,800 people participated on the spot. There were 16 net forums and 17 sessions were formed in Estonian communities overseas. An online pledge bank was established that listed ideas and solutions.

The organisers' goal was also to find new community leaders to take the lead in implementing the solutions.

Whilst the participants mostly took responsibility for implementing solutions on their own initiative, some tasks were assigned to municipal governments and other local authorities, as their role was logically seen as being important in local community matters. There were significantly fewer expectations of private sector and government agencies. Some community activities were started on the spot and have already been implemented.

One of the thematic workshops has evolved into a new initiative to design user-centric public services. Working with two local government administrations, the project uses web 2.0 tools in public services design, e.g. mapping and delegating services to local communities and civil society organizations.

\section{Garage48}

Garage 48 is a boot-camp-style initiative to build new services in just 48 hours. It takes place twice a year in Estonia and is open to participants from all countries. The organisers provide a creative environment for participants to get from an idea to a working prototype or service within one weekend (48 hours).

The events draw voluntary teams of programmers, web developers, designers, marketers and business developers to show that startup companies can be started with really lean budget and with low costs.

Ad-hoc teams are supported to continue working on started ideas after the weekend and form start-ups.

\section{How to get there?}

We have established that for E-Participation to happen at all, it requires some important building blocks to be in place, and to be sustainable there must be a community of E-Participators that grows with each project; I then argued that satisfying the demand for participation at different intensity levels is essential to maintaining this community. If nothing else, an E-Participation project should ensure that users feel their effort has not been wasted and that it would be worth participating in the future. How can a government ensure that it satisfies this demand and, ultimately, paves the way towards a future of Wikipedia-style government?

On the basis of what I have learned from the many projects that I have been involved with, I would now like to make some concrete recommendations on how to make the vision a reality.

If citizens make the effort to contribute to an online participation exercise, or to such a complicated process as law-making, it is important that civil servants are willing to hold a dialogue with them and are open and transparent in their decision-making. Officials should show the same degree of commitment as citizens do: every input deserves a well-argued, comprehensive and nonbureaucratic answer and further discussion. This has not always taken place, and is a possible explanation for why the TOM project eventually petered out. The same goes for elected representatives: it is relatively easy in Estonia to "befriend" MPs, even outside campaigning times. 
However it is still rare to find elected representatives or public officials who make a consistent effort in interacting with constituents, using electronic channels.

I believe that civil servants and politicians should actively participate in all relevant online discussions, regardless of whether the channel is government-provided. This takes political will and commitment, but it is an important way of increasing citizens' trust towards state institutions and the rule of law and strengthening the community of E-Participators.

If you want citizens to E-Participate, it is important that they have the tools to allow them to participate on the level they feel happy with, whether power user, friend or fan. The most important tool is information: without being fully informed about what decisions are made and how, and having background information, citizens cannot be expected to have informed discussions and hold their representatives to account.

In Estonia, there are several examples where officials put information online as a matter of course: osale.ee is the consultation platform that all government agencies can use to publish information such as draft policy papers and conduct consultations (although some ministries use it more than others), and since 2010 government documentation registers have been made public and full-text searchable. We haven't gone far enough in open data terms, though: I would like to see something similar to the open data initiatives in the US and UK, namely data.gov and data.gov.uk. It wouldn't be too difficult for us to do this by modifying the X-Road platform.

In tiny localities - in Estonia, populations in the hundreds are not rare - where it seems easy to reach out to citizens and for citizens to have access to services and decision-making without technology, you might argue that transparency is less necessary. But I agree with Chuck Hirt in his comments on the PEP-NET discussion on E-Participation in Eastern Europe, that transparency in making local decisions and taking everyone on board is all the more important; so even in these localities it is important to use Internet tools to promote participation.

Regardless of how intensively people want to E-Participate, without information it is impossible: an E-Voter needs information in order to decide what party to vote for; somebody who wants to discuss policy on osale.ee needs to have policy documents to argue authoritatively; a campaigner for reduction in speed limits needs to have statistics on road deaths; the hackers like the Garage48 participants who make tools out of government data sets need machine-readable data to work with.

In short: governments should get as much of their information "out there" as possible, and be responsive to the information it receives.

In the future, we should be willing to co-work with anyone who is ready to contribute, regardless of how much they wish to contribute: just like Wikipedia. Crowd-sourcing is not a threat to democracy, quite the opposite. Government will still be the platform for decision-making, but any modern platform needs community support - it needs "fans", "friends" and "power users" to thrive; this is the community that I described above. It is clear that online deliberation needs some structure and regulation, in order to be ethical, constructive and lead to tangible results.

Finally, keep an eye on what it is that you are ultimately aiming to achieve. On the one hand, it is very important to get the technology right because if you don't have the necessary infrastructure, or if you have tools that are complicated and unreliable, people will not participate. On the other, look beyond the technology to the ultimate impact you want: in projects like My Estonia, the important thing is not the technology itself but the co-working and the participation that it allows, and not just about the number of comments and visitor figures but about the lasting effect that is left on the EParticipation community by ensuring that people who take part in E-Participation initiatives are motivated to be involved in the future. This is the real meaning of sustainable E-Participation.

\section{Conclusion}

To sum up, I have set out a vision of a Wikipedia-inspired state that is a platform where decisions are made, but is open to work with anybody who wishes to participate - regardless of how much they want to contribute. For this to be a success, it is essential to foster a community of 
E-Participators, a diverse group of citizens ranging from the power-users - the community organisers and local campaigners - to the "fans" - for example spectators who contribute less often but still participate at a lower intensity. Satisfying this spectrum of demand by offering diverse E-Participation opportunities will lead to a growing E-Participation community; for this to happen, governments need to meet citizens' commitment and investment of time with an equal commitment by entering into a real dialogue and working together to make decisions transparently. Open information and data is an important part of this.

By maintaining this community of E-Participators - the fans, friends and power-users - on a solid base of IT infrastructure, online tools and digital literacy, a government will be able to call upon a rich resource and work with citizens to meet their needs much more closely than they are able to today. Whatever new technology comes along, and however successful individual projects are, neglecting to maintain this fertile ground will only lead to E-Participation failure.

\section{References}

Garage48 (n.d.). From idea to service in 48 hours! Retrieved 16 September, 2010, from http://www.garage48.org/en Heaven, J. (2010). Summary of Live Chat with Hille Hinsberg. Discussing European eParticipation. PEP-NET-Blog. Retrieved 16 September, 2010, from http://tinyurl.com/pepnetdiscourse

Hinsberg, H. (2007-2010). Osale: the Estonian eParticipation tool. Retrieved 16 September, 2010, from http://epractice.eu/cases/osale

Lathrop, D., \& Ruma, L. (Eds.) (2010). Open Government. Collaboration, Transparency and Participation in Practice. O'Reilly Media

My Estonia citizen initiative (n.d.). Retrieved 16 September, 2010, from http://www.minueesti.ee/

NENO, Network of Estonian Nonprofit Organisations (2002). Estonian Civil Society Development Concept. Retrieved 16 September, 2010, from www.ngo.ee/7337

Reinsalu, K. (2010). Handbook on eDemocracy, the EPACE theme publication, Retrieved 16 September, 2010, from http://www.kansanvalta.fi/en/Etusivu/Tutkimusjakehitys/EPACE/EPACEjulkaisutpa

RISO, State Information System (2002) Estonian Information Society Strategy 2013. Retrieved 16 September, 2010, from http://www.riso.ee/en/information-policy/policy-document

Today I Decide + (n.d.). The TID+ Project. Retrieved 16 September, 2010, from http://tidplus.net/project/

Vassil, K. (2007). Participation factors and experience in e-voting: comparative analysis based on local government elections in 2005 and parliament elections in 2007. Unpublished Master Thesis (University of Tartu, Department of Journalism and Communications).

VOLIS, the information system for local councils (n.d.). In English. Retrieved 16 September, 2010, from http://dw.riik.ee/VOLIS/In English

\section{About the Author}

Hille Hinsberg

The Author has experience in the academic and NGO sectors. She has worked as a spokesperson for the Non-Estonians' Integration Foundation and has carried out several EU-financed projects concerning social integration, cultural diversity and participation. Working for the Government Office in Estonia, Hille is actively involved in establishing communication channels between citizens and government institutions. She promotes the implementation of good engagement practices and advises government agencies on participation and E-Participation issues. Hille is responsible for osale.ee, the central participation portal for e-consultations. 